\title{
Acetylcholinesterase-independent protective effects of huperzine A against iron overload-induced oxidative damage and aberrant iron metabolism signaling in rat cortical neurons
}

\author{
Ling-xue TAO, Xiao-tian HUANG, Yu-ting CHEN, Xi-can TANG, Hai-yan ZHANG* \\ CAS Key Laboratory of Receptor Research, Shanghai Institute of Materia Medica, Chinese Academy of Sciences, Shanghai 201203, \\ China
}

\begin{abstract}
Aim: Iron dyshomeostasis is one of the primary causes of neuronal death in Alzheimer's disease (AD). Huperzine A (HupA), a natural inhibitor of acetylcholinesterase (AChE), is a licensed anti-AD drug in China and a nutraceutical in the United Sates. Here, we investigated the protective effects of HupA against iron overload-induced injury in neurons.

Methods: Rat cortical neurons were treated with ferric ammonium citrate (FAC), and cell viability was assessed with MTT assays. Reactive oxygen species (ROS) assays and adenosine triphosphate (ATP) assays were performed to assess mitochondrial function. The labile iron pool (LIP) level, cytosolic-aconitase (c-aconitase) activity and iron uptake protein expression were measured to determine iron metabolism changes. The modified Ellman's method was used to evaluate AChE activity.

Results: HupA significantly attenuated the iron overload-induced decrease in neuronal cell viability. This neuroprotective effect of HupA occurred concurrently with a decrease in ROS and an increase in ATP. Moreover, HupA treatment significantly blocked the upregulation of the LIP level and other aberrant iron metabolism changes induced by iron overload. Additionally, another specific AChE inhibitor, donepezil (Don), at a concentration that caused AChE inhibition equivalent to that of HupA negatively, influenced the aberrant changes in ROS, ATP or LIP that were induced by excessive iron.

Conclusion: We provide the first demonstration of the protective effects of HupA against iron overload-induced neuronal damage. This beneficial role of HupA may be attributed to its attenuation of oxidative stress and mitochondrial dysfunction and elevation of LIP, and these effects are not associated with its AChE-inhibiting effect.
\end{abstract}

Keywords: Alzheimer's disease; huperzine A; iron; reactive oxygen species; mitochondria dysfunction; acetylcholinesterase

Acta Pharmacologica Sinica (2016) 37: 1391-1400; doi: 10.1038/aps.2016.78; published online 8 Aug 2016

\section{Introduction}

Alzheimer's disease (AD) is a progressive neurodegenerative disease and the leading cause of dementia among the elderly worldwide ${ }^{[1,2]}$. Although the enhancement of central cholinergic transmission with acetylcholinesterase (AChE) inhibitors has been proven to be clinically effective for symptomatic treatment, no potent disease-modifying treatment is currently available $^{[3]}$. Therefore, it is vitally important to understand the complicated pathogenesis of AD to achieve further progress.

Mounting evidence suggests that the accumulation of iron in specific areas of the brain is a hallmark and one of the primary causes of neurodegenerative diseases including

\footnotetext{
${ }^{*}$ To whom correspondence should be addressed. E-mail hzhang@simm.ac.cn

Received 2016-02-17 Accepted 2016-04-05
}

$\mathrm{AD}^{[4-6]}$. Abnormally high iron concentrations in the brain have been widely reported in AD patients ${ }^{[7,8]}$, and the well-known APP/PS1 transgenic mouse AD animal model ${ }^{[9]}$. Additionally, excess iron has been proven to cause neuronal damage in multiple in vitro and in vivo studies ${ }^{[10-12]}$ because excess iron can generate reactive oxygen species (ROS) ${ }^{[13]}$ and is closely associated with mitochondrial dysfunction ${ }^{[14]}$. Correspondingly, therapeutic strategies targeting iron dyshomeostasis have recently attracted considerable attention and have been both preclinically and clinically demonstrated to effectively decrease the progression of the neurological symptoms of $\mathrm{AD}^{[15-18]}$. Together, these results indicate that the identification of key therapeutic targets for treating iron dyshomeostasis and the discovery of active small molecules that target ironmediated neuronal damage may shed new light on the development of effective therapeutic agents for AD treatment. 
Huperzine A (HupA) (Figure 1), an alkaloid isolated from the Chinese herbal medicine Qian Ceng Ta (Huperzia serrata), possesses a potent AChE inhibitory effect and is a licensed drug that is widely used for AD treatment in China and is available as a nutraceutical in the United States ${ }^{[19]}$. Interestingly, increasing numbers of studies have demonstrated that HupA can ameliorate oxidative stress and mitochondrial dysfunction $^{[20-22]}$. First, HupA significantly suppresses ROS overproduction and lipid peroxidation in $\mathrm{A} \beta{ }^{[23,24]}, \mathrm{H}_{2} \mathrm{O}_{2^{-}}{ }^{[25]}$ and glutamate $^{[26]}$-stimulated cellular models. Second, HupA also markedly ameliorates oxidative stress in chronic cerebrally hypoperfused and aged rats ${ }^{[27,28]}$ and attenuates mitochondrial dysfunction in APP/PS1 transgenic mice ${ }^{[29]}$ and rats after intracerebral hemorrhage $(\mathrm{ICH})^{[30]}$. It has been suggested that ICH causes significant iron overload in the brain ${ }^{[31]}$, and the levels of brain iron in APP/PS1 transgenic mice are markedly greater than those in aged-matched control mice ${ }^{[9]}$. Together, the evidence indicates that excessive iron accumulation in neuronal cells is closely associated with massive oxidative damage and mitochondrial dysfunction, which subsequently lead to neurotoxicity ${ }^{[14,32]}$. Therefore, it is of great interest to determine whether HupA can ameliorate iron overload-induced neuronal damage and whether these effects could be attributable to its anti-oxidative capacity or its regulation of iron metabolism. Additionally, because HupA is a potent AChE inhibitor, it is necessary to further clarify whether its influence on AChE activity is associated with the above-mentioned beneficial effects.

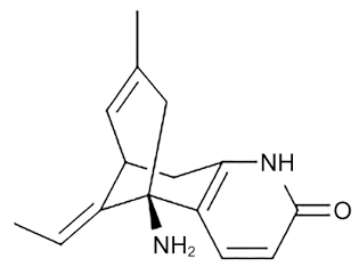

Figure 1. The chemical structure of HupA.

\section{Materials and methods Materials}

HupA (purity $>99 \%$, Wan Bang Pharmaceutical Co Ltd, Wenling, China) was dissolved in $0.1 \mathrm{~mol} / \mathrm{L} \mathrm{HCl}$ at $5 \mathrm{mg} / \mathrm{mL}$ as a stock solution. Stock solutions of ferric ammonium citrate (FAC, Sigma-Aldrich, St Louis, MO, USA), deferoxamine (Sigma-Aldrich, St Louis, MO, USA) and donepezil hydrochloride (King-Pharm, Nanjing, China) were prepared in deionized water at $10 \mathrm{mmol} / \mathrm{L}$. All solutions were stored at $-20^{\circ} \mathrm{C}$ and diluted to the proper concentrations before use.

\section{Primary cortical neuron culture and drug treatment}

Primary neuronal cultures were prepared from embryonic day 16-17 (E16-17) embryos of Sprague-Dawley rats as previously described with slight modifications ${ }^{[33]}$. Briefly, the cortices were rapidly dissected from the whole-brain tissues in ice- cold high-glucose Dulbecco's modified Eagle's medium (HGDMEM, Invitrogen, Carlsbad, CA, USA), minced and dissociated in $0.125 \%$ trypsin with $0.2 \mathrm{mg} / \mathrm{mL}$ DNase I at $37^{\circ} \mathrm{C}$ for 15 min. Next, the tissues were triturated with pipettes in HGDMEM with 10\% fetal bovine serum (FBS, Gibco, Carlsbad, CA, USA) and filtered through a strainer (300/400 mesh). The cell suspensions were then plated into poly-L-lysine (Sangon Biotech, Shanghai, China)-coated plates or dishes. After $4 \mathrm{~h}$ of incubation, the culture medium was completely removed, and the cortical neurons were cultured in neurobasal medium (Invitrogen, Carlsbad, CA, USA) with $0.5 \mathrm{mmol} / \mathrm{L}$ L-glutamine, 2\% B27 supplement, penicillin $(60 \mathrm{mg} / \mathrm{L})$ and streptomycin $(50 \mathrm{mg} / \mathrm{L})$. Half of the culture medium was refreshed every $3 \mathrm{~d}$. After $9 \mathrm{~d}$ of culture, the culture medium was replaced with neurobasal medium (without B27 supplement), and the neurons were then treated with different concentrations of FAC with or without HupA for 24 h, whereas the control group was maintained in same amount of culture medium.

\section{Cell viability assay}

Primary cortical neurons cultured in 96-well plates were treated on the 9 th day. After the application of the different treatments for $24 \mathrm{~h}$, cell viability was measured using the 3-(4,5-dimethylthiazol-2-yl)-2,5-diphenyltetrazolium bromide (MTT, Amresco, Solon, OH, USA) reduction assay. The cells were incubated with MTT solution $(5 \mathrm{mg} / \mathrm{mL})$ at $37^{\circ} \mathrm{C}$ for $4 \mathrm{~h}$. All culture media were then removed, and the resultant formazan was dissolved in DMSO $(100 \mu \mathrm{L} /$ well $)$. Next, the plates were shaken for $5 \mathrm{~min}$, and the absorbance was measured using a PerkinElmer microplate reader at $490 \mathrm{~nm}$. The optical density $(O D)$ values of all groups were normalized against the values of the control, and the cell viabilities are presented as the percentages of surviving cells relative to the control group. At least three independent experiments were performed.

\section{Measurement of intracellular ROS}

ROS generation was measured based on the oxidation of $2^{\prime}, 7^{\prime}$-dichlorofluorescein diacetate $\left(\mathrm{H}_{2} \mathrm{DCF}\right.$-diacetate) to fluorescent $2^{\prime}, 7^{\prime}$-dichlorofluorescein (DCF). Twenty-four hours after the different treatments, the cells in 96-well plates were incubated with $10 \mu \mathrm{mol} / \mathrm{L}$ of $\mathrm{H}_{2} \mathrm{DCF}$-diacetate (Molecular Probes, Carlsbad, CA, USA) at $37^{\circ} \mathrm{C}$ in the dark for $45 \mathrm{~min}$. The DCF intensities were quantified using a PerkinElmer microplate reader with 485-nm excitation and 520-nm emission filters. The fluorescence intensities were normalized to the control group and are presented as the relative ROS levels.

\section{Detection of adenosine triphosphate (ATP) production}

The neuronal ATP levels were measured using a bioluminescent ATP detection kit (Promega, Madison, WI, USA). After treatment, the cells in the 96-well plates were left at room temperature for $30 \mathrm{~min}$ and then lysed via the addition of the ATP-releasing reagent $(100 \mu \mathrm{L} /$ well). The lysates were incubated in the dark with the luciferin substrate and luciferase enzyme for $10 \mathrm{~min}$ to stabilize the luminescent signal. The 
bioluminescence intensity was measured using a PerkinElmer microplate reader. The bioluminescence intensities were normalized to those of the control group and are presented as the relative ATP levels.

\section{Measurement of the labile iron pool (LIP) level}

The cellular labile iron was measured with a fluorescence technique using the iron sensor calcein $(\mathrm{CA})^{[34]}$. After treatment for $24 \mathrm{~h}$, the cultures were washed three times with phosphate buffer solution (PBS) to remove the extracellular iron and then loaded with $0.25 \mu \mathrm{mol} / \mathrm{L}$ calcein acetomethoxy (CA-AM) (Molecular Probes, Carlsbad, CA, USA) for $30 \mathrm{~min}$ at $37^{\circ} \mathrm{C}$ in the dark. After loading, the cultures were washed twice with PBS to remove the excess CA-AM, and the cellular CA fluorescence intensity was measured using a PerkinElmer microplate reader at an excitation wavelength of $485 \mathrm{~nm}$ and an emission wavelength of $535 \mathrm{~nm}$. The changes in the CA fluorescence intensities were equivalent to the amounts of cellular iron that were originally bound to the CA and proportional to the LIP level. The fluorescence intensities are presented as the percentages of the FAC group.

\section{Protein extraction and Western blot analysis}

Cells in 6-well plates were washed twice with ice-cold PBS and lysed in RIPA buffer (50 mmol/L Tris- $\mathrm{HCl}, 150 \mathrm{mmol} / \mathrm{L} \mathrm{NaCl}$, $0.5 \%$ sodium deoxycholate, $1 \%$ Triton $\mathrm{X}-100,0.1 \%$ SDS, 1 $\mathrm{mmol} / \mathrm{L} \mathrm{NaF}, 1 \mathrm{mmol} / \mathrm{L} \mathrm{Na}_{3} \mathrm{VO}_{4}, 1 \mathrm{mmol} / \mathrm{L} \mathrm{PMSF}, 1 \% \mathrm{P} 8340$, $\mathrm{pH} 7.4$ ) for $30 \mathrm{~min}$ on ice and then centrifuged at $12000 \times \mathrm{g}$ for $15 \mathrm{~min}$ at $4{ }^{\circ} \mathrm{C}$. The resulting supernatants were collected, and the protein concentrations were determined using a BCA assay kit (Pierce, Rockford, IL, USA).

The protein samples were mixed with loading buffer containing 5\% DTT and boiled for $10 \mathrm{~min}$. The proteins were separated by sodium dodecyl sulfonate-polyacrylamide gel electrophoresis (SDS-PAGE) and then transferred to nitrocellulose membranes. The membranes were blocked with nonfat milk for $1 \mathrm{~h}$ at room temperature and subsequently incubated with the following primary antibodies overnight: $\beta$-actin (SigmaAldrich, St Louis, MO, USA), transferrin receptor 1 (TfR1; Invitrogen, Carlsbad, CA, USA), and divalent metal transporter 1 (DMT1; Alpha Diagnostic International, San Antonio, TX, USA). The membranes were washed with Tris-buffered saline with Tween-80 (TBST) and then incubated with horseradish peroxidase-conjugated anti-mouse or anti-rabbit antibody (Kangchen, Shanghai, China) for $1 \mathrm{~h}$ at room temperature. The signals were detected using the ECL Plus detection kit (Amersham GE Healthcare, Piscataway, NJ, USA). The immunoreactive bands were visualized via autoradiography, and the intensity of each band was quantified.

Cytosol purification and cytosolic-aconitase (c-aconitase) activity assay

After $24 \mathrm{~h}$ of the different treatments, the neurons were washed and harvested with cold HEPES buffer $(100 \mathrm{mmol} / \mathrm{L}$ HEPES, $250 \mathrm{mmol} / \mathrm{L}$ sucrose, $\mathrm{pH} 7.4$ ) and then treated with $0.007 \%$ digitonin on ice for $10 \mathrm{~min}$. Next, the cell lysates were ultracentrifuged at $100000 \times g$ for $1 \mathrm{~h}$ at $4^{\circ} \mathrm{C}$. The cytosolic fraction (supernatant) was tested for its protein concentration and immediately used to test the aconitase activity.

The aconitase activities were measured in the fresh cytosolic extracts with $50 \mu \mathrm{g}$ of the cytosolic extract as the substrate in $0.1 \mathrm{~mol} / \mathrm{L}$ Tris- $\mathrm{HCl}$ buffer $(\mathrm{pH} 7.4)$ at $37^{\circ} \mathrm{C}^{[35]}$. The disappearance of the cis-aconitate was monitored spectrophotometrically at $240 \mathrm{~nm}$. The units correspond to nmol of substrate consumed/min, and $\varepsilon=3.6 \mathrm{mmol}^{-1} \times \mathrm{cm}^{-1}$.

\section{AChE activity assay}

After the different treatments for $24 \mathrm{~h}$, the cells in the 6-well plates were washed with cold $0.1 \mathrm{~mol} / \mathrm{L}$ PBS twice, scraped with $0.1 \mathrm{~mol} / \mathrm{L}$ PBS buffer [0.5 \% Triton, $0.05 \mathrm{mmol} / \mathrm{L}$ ethylenediamine tetraacetic acid (EDTA)] and homogenized. The homogenates were centrifuged at $14000 \times g$ for $5 \mathrm{~min}$ at $4^{\circ} \mathrm{C}$. The supernatants were used for the determination of $\mathrm{AChE}$ activity via a 96-well microplate assay based on Ellman's method $^{[36]}$ with modifications. Thirty microliters of $2 \mathrm{mmol} / \mathrm{L}$ acetylthiocholine iodide (S-ACh), $50 \mu \mathrm{L}$ of $0.2 \% 5,5^{\prime}$-dithiobis (2-nitrobenzoic acid) (DTNB, Sigma-Aldrich, St Louis, MO, USA), $5 \mu \mathrm{L}$ of $4 \mathrm{mmol} / \mathrm{L}$ tetraisopropyl pyrophosphoramide (iso-OMPA), $10 \mu \mathrm{L}$ of $0.1 \mathrm{~mol} / \mathrm{L} \mathrm{PB}$ buffer, $109 \mu \mathrm{L}$ of $\mathrm{H}_{2} \mathrm{O}$ and $50 \mu \mathrm{L}$ of sample were added to the 96-well plates, which were then shaken for $20 \mathrm{~min}$ at $37^{\circ} \mathrm{C}$. Next, $10 \mu \mathrm{L}$ of $3 \%$ SDS was added to stop the reaction, and the production of the yellow anion of 5-thio-2-nitrobenzoic acid was measured using a PerkinElmer microplate reader at $450 \mathrm{~nm}$.

\section{Statistical analysis}

The data are presented as the mean \pm SEM and were analyzed using one-way ANOVA with Dunnett's test. P-values below 0.05 were considered significant. The statistical results are reported in the figure legends.

\section{Results}

HupA attenuated the decrease in survival of FAC-exposed rat cortical neurons

We first examined the effects of HupA treatment on iron overload-induced neurotoxicity. To confirm the neuronal toxicity of iron, we used FAC as a source of iron. We first assessed the effects of FAC exposure at different concentrations (25-200 $\mu \mathrm{mol} / \mathrm{L})$ on the cell viabilities of the cortical neurons. The viabilities of the cells incubated with FAC at 25, 50, 100, and $200 \mathrm{mmol} / \mathrm{L}$ for $24 \mathrm{~h}$ were $95.46 \%, 92.16 \%, 85.03 \%$, and $82.54 \%$ of the control group, respectively (Figure 2A). FAC exhibited concentration-dependent effects, and the cell viabilities of the rat cortical neurons were significantly decreased by FAC exposure at concentrations greater than $50 \mu \mathrm{mol} / \mathrm{L}$ (Figure 2A). We used FAC at the concentration of $100 \mu \mathrm{mol} / \mathrm{L}$ in the subsequent experiments. The viability of the neurons decreased to $85 \%$ of the control group upon incubation with $100 \mu \mathrm{mol} / \mathrm{L}$ FAC (Figure $2 \mathrm{~B}, P<0.01$ vs the control group), whereas treatment with $1 \mu \mathrm{mol} / \mathrm{L}$ or $10 \mu \mathrm{mol} / \mathrm{L}$ HupA markedly increased the cell viabilities to $90.90 \%$ and $97.04 \%$, respectively (Figure $2 \mathrm{~B}, P<0.05$ and $P<0.01$ vs FAC-treated group, respectively). 

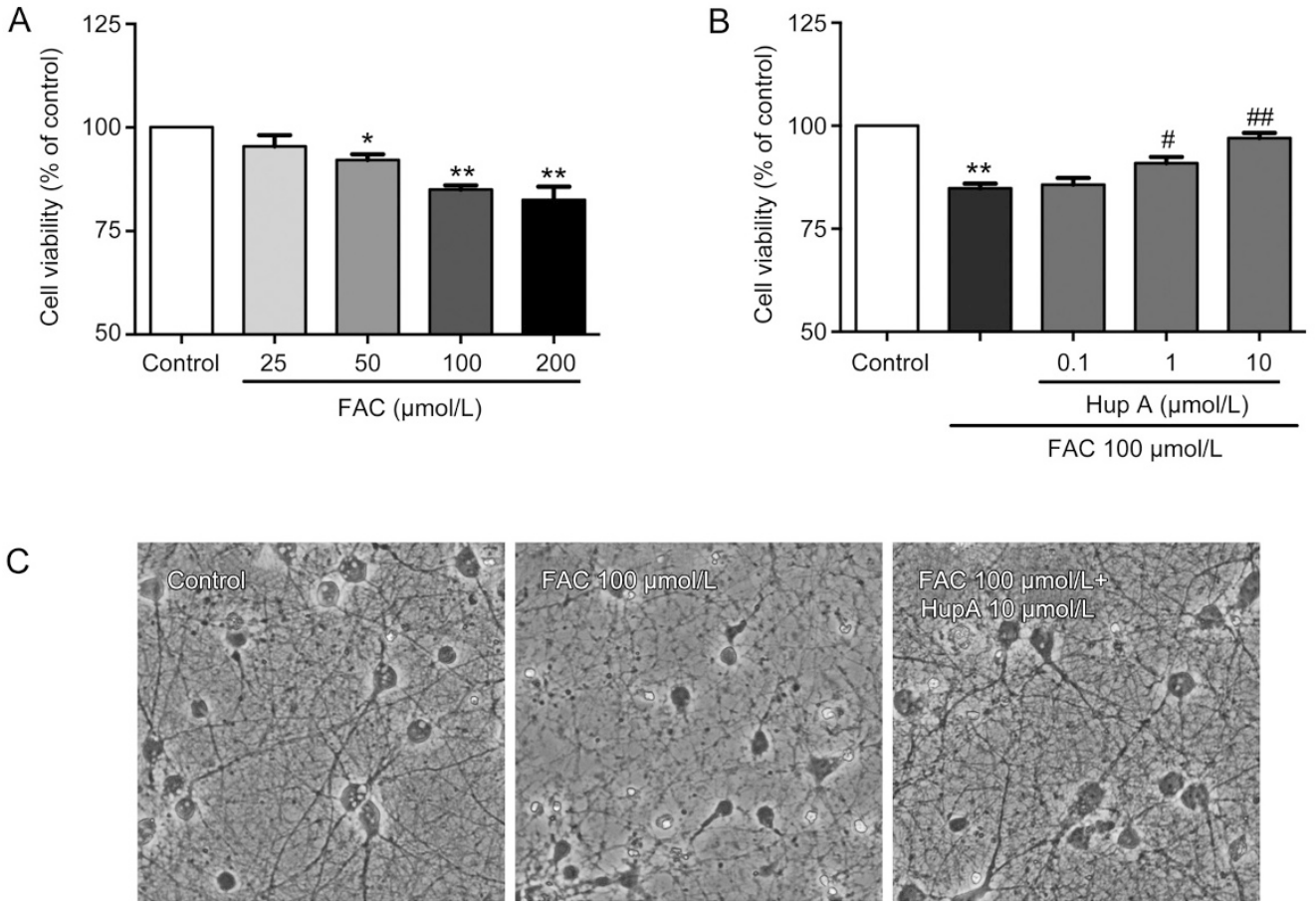

Figure 2. Effects of HupA on cell injury induced by iron overload in rat cortical neurons. (A) Rat cortical neurons were treated with FAC (25, 50 , 100, or $200 \mu \mathrm{mol} / \mathrm{L}$ ) for $24 \mathrm{~h}$. Cell viability was estimated using MTT assays. $n=4$. (B) Rat cortical neurons were treated with HupA (0.1, 1, or $10 \mu \mathrm{mol} / \mathrm{L}$ ) and $100 \mu \mathrm{mol} / \mathrm{L}$ FAC for $24 \mathrm{~h}$. $n=4$. (C) The morphological changes were observed using phase-contrast microscopy (200×). Data were expressed as percentage of control group, and shown as mean \pm SEM. ${ }^{*} P<0.05,{ }^{* *} P<0.01$ vs control group. ${ }^{\#} P<0.05,{ }^{\# \#} P<0.01$ vs FAC group.

Morphological changes were also assessed in the present study. As illustrated in Figure 2C, the neuronal numbers decreased, and some neurons lost neurites or were replaced by debris after exposure to $100 \mu \mathrm{mol} / \mathrm{L} \mathrm{FAC}$ for $24 \mathrm{~h}$. In contrast, the cells exposed to the same amount of FAC and treated with $10 \mu \mathrm{mol} / \mathrm{L}$ of HupA exhibited preserved neuronal morphologies (Figure 2C).

\section{HupA inhibited ROS formation in the FAC-exposed rat cortical neurons}

We next evaluated the effects of HupA on ROS formation in the excessive iron-stimulated neurons because the ROS increment induced by intracellular iron is the crucial mediator of iron overload-associated neurotoxicity ${ }^{[37]}$. As illustrated in Figure 3, the levels of intracellular ROS were significantly increased to $175.80 \%$ in the primary rat cortical neurons incubated with FAC for $24 \mathrm{~h}$ compared with the control neurons $(P<0.01)$. The positive control with the iron chelator deferoxamine (DFO) at $100 \mu \mathrm{mol} / \mathrm{L}$ exhibited a complete reversal of the ROS overproduction. Treatment with HupA at 1 and 10 $\mu \mathrm{mol} / \mathrm{L}$ significantly decreased the ROS level increments to $146.81 \%$ and $137.97 \%(P<0.05$ and $P<0.01)$, respectively, compared with the group that was treated with only FAC (Figure 3).

HupA ameliorated the ATP decrease in the FAC-exposed rat cortical neurons

Mitochondria play a critical role in iron overload-associated

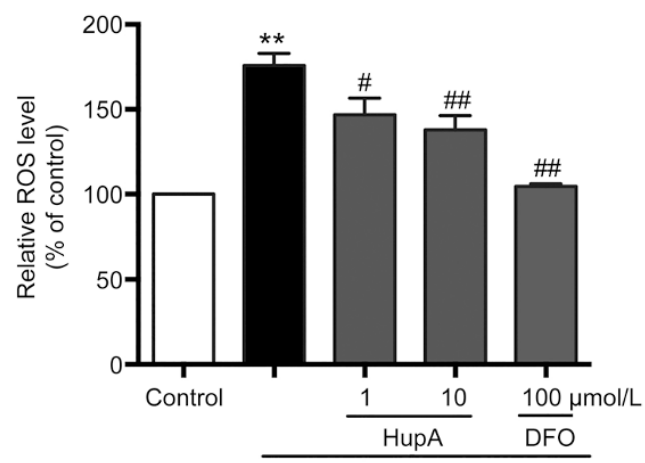

FAC $100 \mu \mathrm{mol} / \mathrm{L}$

Figure 3. Effects of HupA on the level of intracellular ROS in FAC-exposed rat cortical neurons. FAC $(100 \mu \mathrm{mol} / \mathrm{L})$ caused a significant increase in the formation of ROS in neurons, which was significantly attenuated by both HupA ( 1 and $10 \mu \mathrm{mol} / \mathrm{L})$ and DFO (100 $\mathrm{mmol} / \mathrm{L})$. ROS was detected by DCF-DA. $n=7$. Data were expressed as percentage of control group, and shown as mean \pm SEM. ${ }^{* *} P<0.01$ vs control group. ${ }^{\#} P<0.05,{ }^{\# \#} P<0.01$ vs FAC group.

toxicity. Therefore, we conducted an ATP assay to evaluate the mitochondrial function of the FAC-exposed neurons that were treated with or without HupA. The results revealed that the level of ATP was significantly decreased to $85.59 \%$ after incubation with $100 \mu \mathrm{mol} / \mathrm{L}$ of FAC for $24 \mathrm{~h}$ (Figure 4, $P<0.01$ $v s$ control neurons), and $100 \mu \mathrm{mol} / \mathrm{L}$ of DFO treatment markedly reversed this increase ( $P<0.01$ vs the FAC group). Treat- 


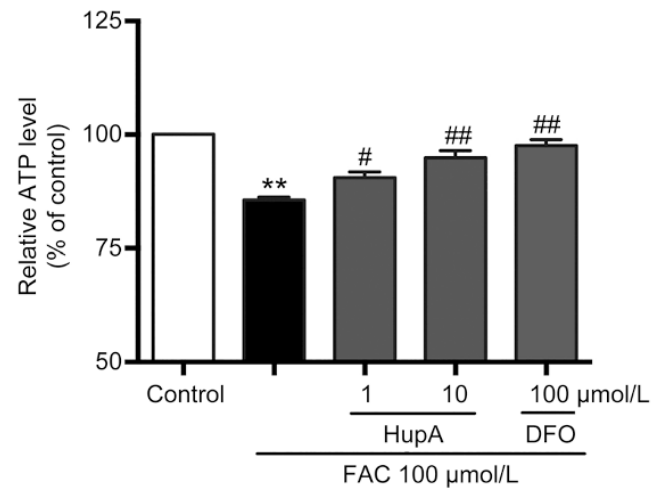

Figure 4. Effects of HupA on the level of ATP in FAC-exposed rat cortical neurons. FAC $(100 \mu \mathrm{mol} / \mathrm{L})$ caused a significant reduction of ATP, which was ameliorated by both HupA ( 1 and $10 \mu \mathrm{mol} / \mathrm{L})$ and DFO (100 $\mu \mathrm{mol} / \mathrm{L})$; $n=4$. Data were expressed as percentage of control group, and shown as mean \pm SEM. ${ }^{* *} P<0.01$ vs control group. ${ }^{\#} P<0.05,{ }^{\# \#} P<0.01$ vs FAC group.

ment with HupA at 1 and $10 \mu \mathrm{mol} / \mathrm{L}$ significantly enhanced the production of ATP to $92.71 \%$ and $95.66 \%(P<0.05$ and $P<0.01$, Figure 4), respectively, compared with those in the group treated with FAC alone.

\section{HupA decreased labile iron pool (LIP) levels of FAC-exposed rat} cortical neurons

We next assessed the effects of HupA treatment on the LIP after treatment with FAC because the LIP represents the metabolically active forms of intracellular iron. As illustrated in Figure 5, exposure to FAC at $100 \mu \mathrm{mol} / \mathrm{L}$ for $24 \mathrm{~h}$ resulted in a robust increase in the LIP level ( $P<0.01$ vs control group) in the cortical neurons, whereas DFO treatment at $100 \mu \mathrm{mol} / \mathrm{L}$ of significantly decreased the increased LIP levels induced by FAC $(P<0.01$ vs the FAC group). Treatment with HupA at 1 and $10 \mu \mathrm{mol} / \mathrm{L}$ significantly decreased the intracellular LIP levels compared with those in the group treated with FAC alone (Figure 5, $P<0.05$ and $P<0.01$, respectively).

HupA upregulated the expression of TfR1 and DMT1 and downregulated the activity of c-aconitase in the FAC-exposed rat cortical neurons

Because previous studies have reported that TfR1, DMT1 and c-aconitase are important proteins involved in iron metabolism, we further evaluated the influence of HupA on the expression of TfR1 and DMT1 and the activity of c-aconitase in the FAC-exposed cortical neurons. TfR1 expression was significantly decreased in the rat cortical neurons after FAC treatment for $24 \mathrm{~h}$ (Figure 6A, $P<0.01$ vs the control group), whereas both $100 \mu \mathrm{mol} / \mathrm{L}$ of DFO and $10 \mu \mathrm{mol} / \mathrm{L}$ of HupA significantly ameliorated the decreased TfR1 expression induced by FAC (Figure 6A, $P<0.01$ vs the FAC group). The effect of HupA on the expression of DMT1 was similar to that of TfR1 (Figure 6B, $P<0.05$ or $P<0.01$ vs the FAC group). In contrast to the pattern of change for TfR1, FAC at $100 \mu \mathrm{mol} / \mathrm{L}$ significantly increased the c-aconitase activity $(P<0.01$ vs control group), whereas $10 \mu \mathrm{mol} / \mathrm{L}$ HupA treatment significantly

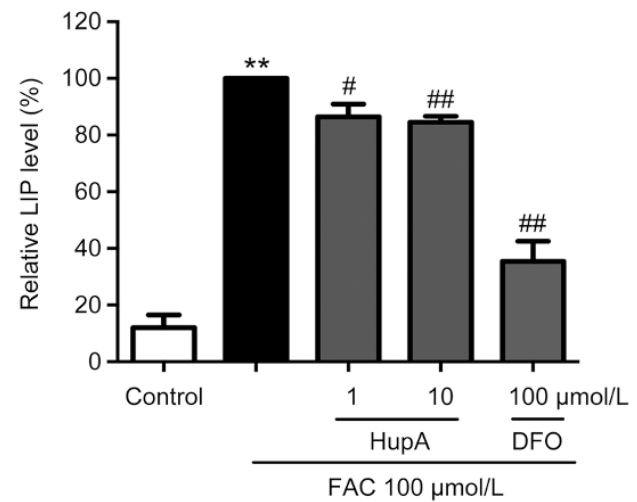

Figure 5. Effects of HupA on the level of LIP in FAC-exposed rat cortical neurons. FAC $(100 \mu \mathrm{mol} / \mathrm{L})$ incubation caused a significant increase of LIP, which significantly reduced by both HupA ( 1 and $10 \mu \mathrm{mol} / \mathrm{L}$ ) and DFO (100 $\mu \mathrm{mol} / \mathrm{L})$. LIP was detected by calcein-AM. $n=5$. Data were expressed as percentage of FAC treated group, and shown as mean \pm SEM. ${ }^{* *} P<0.01$ vs control group. ${ }^{\#} P<0.05,{ }^{\# \#} P<0.01$ vs FAC group.

reversed the change in c-aconitase activity in the FAC-exposed cortical neurons (Figure 6B, $P<0.05$ vs the FAC group).

The inhibition of AChE activity had no effect on the ROS, ATP or LIP levels in FAC-exposed rat cortical neurons

We further examined whether the AChE activity contributed to the ameliorative effects of HupA. The specific AChE inhibitor donepezil (Don) was used for comparison. We found that both the treatments with HupA and Don significantly and dose-dependently decreased the AChE activity, and the AChE-inhibiting effect of Don at $1 \mu \mathrm{mol} / \mathrm{L}$ was equivalent to that of HupA at $10 \mu \mathrm{mol} / \mathrm{L}$ (Figure 7A). Don at $1 \mu \mathrm{mol} / \mathrm{L}$ was then selected for the following experiment. In contrast to the ameliorative effects of HupA treatment at $10 \mu \mathrm{mol} / \mathrm{L}, 1$ $\mu \mathrm{mol} / \mathrm{L}$ Don had no observable effects on the iron overloadinduced overproduction of ROS formation or decrease in ATP production in the rat cortical neurons (Figure 7B, 7C, $P>0.05$ vs the FAC group). Similarly, the robustly increased LIP level in the FAC-exposed cortical neurons ( $P<0.01$ vs control group) was not affected by the Don treatment (Figure 7D, $P>0.05$ vs the FAC group).

\section{Discussion}

Although the protective effects of HupA, a highly selective and potent AChE inhibitor, against neuronal damage have been well proven in multiple in vitro neuronal models ${ }^{[26,30,38,39]}$, whether and how this active natural product can directly ameliorate iron overload-induced neuronal damage has not yet been clarified. The most notable aspects of the present study include: 1) the significant effect of HupA on alleviating multifaceted iron overload-induced malignant changes in primary cortical neurons, and 2) the finding that the classical AChEinhibiting effect of HupA may not contribute to its protection against iron-overload-induced neuronal damage.

Iron dysregulation and accumulation in the brain have been found to play critical roles in the etiologies of many 
A
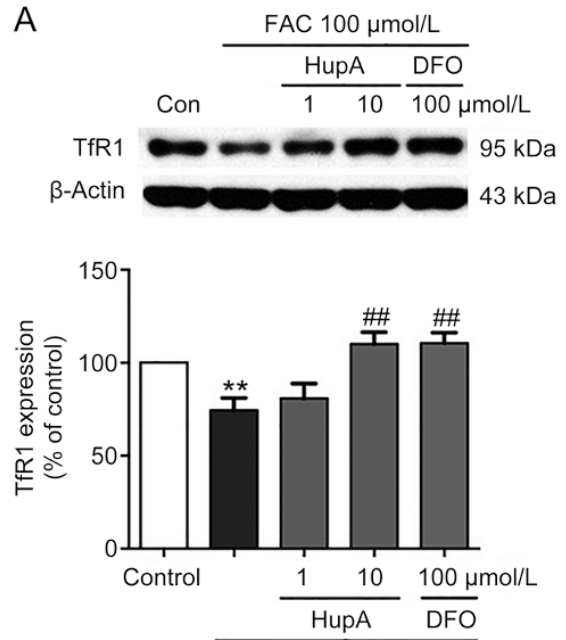

FAC $100 \mu \mathrm{mol} / \mathrm{L}$
B
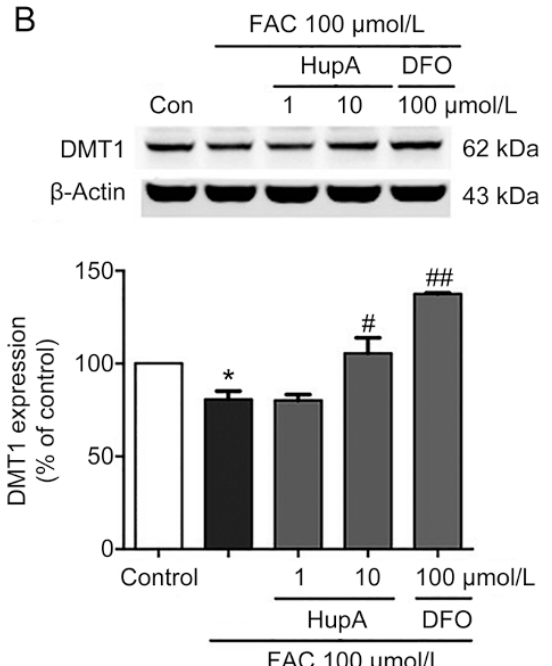

C

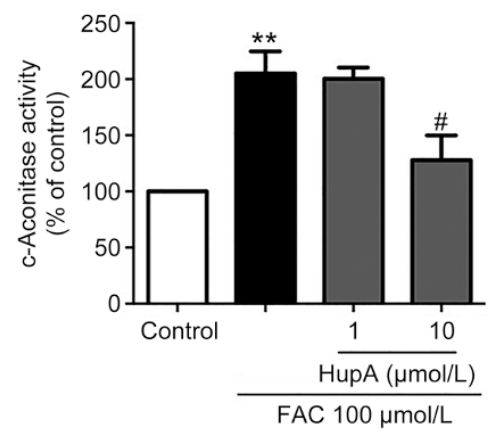

Figure 6. Effects of HupA on the levels of TfR 1 and DMT1 and activity of C-aconitase in FAC-exposed rat cortical neurons. FAC (100 $\mu$ mol/L) incubation caused significant decreases of TfR1 (A) and DMT1 (B) expression, which were significantly reversed by HupA (10 $\mu \mathrm{mol} / \mathrm{L})$ treatment. (C) FAC (100 $\mu \mathrm{mol} / \mathrm{L})$ incubation caused significant increase of C-aconitase activity, which was significantly reversed by HupA $(10 \mu \mathrm{mol} / \mathrm{L})$ treatment. $n=5$. Data were expressed as percentage of FAC treated group, and shown as mean \pm SEM. ${ }^{*} P<0.05,{ }^{* *} P<0.01$ vs control group. ${ }^{\#} P<0.05$, ${ }^{\# \#} P<0.01$ vs FAC group.

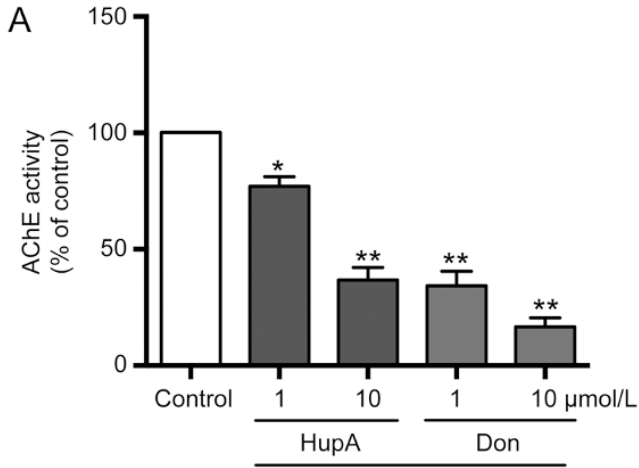

FAC $100 \mu \mathrm{mol} / \mathrm{L}$

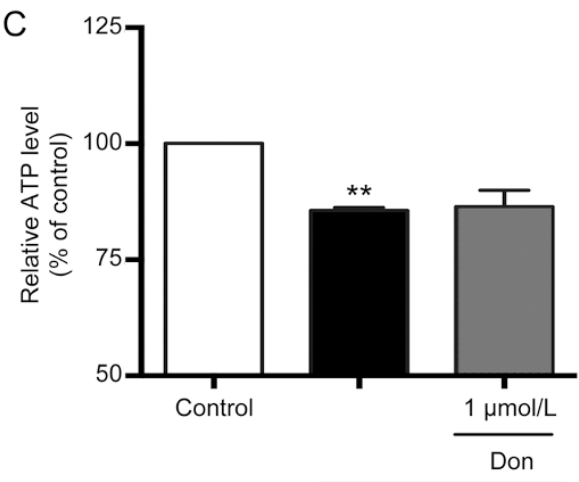

FAC $100 \mu \mathrm{mol} / \mathrm{L}$

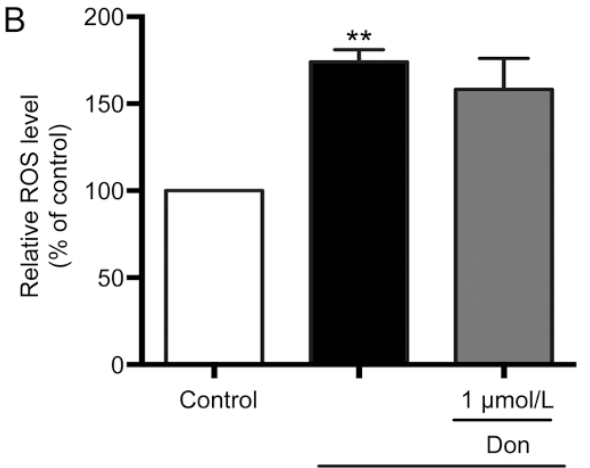

FAC $100 \mu \mathrm{mol} / \mathrm{L}$

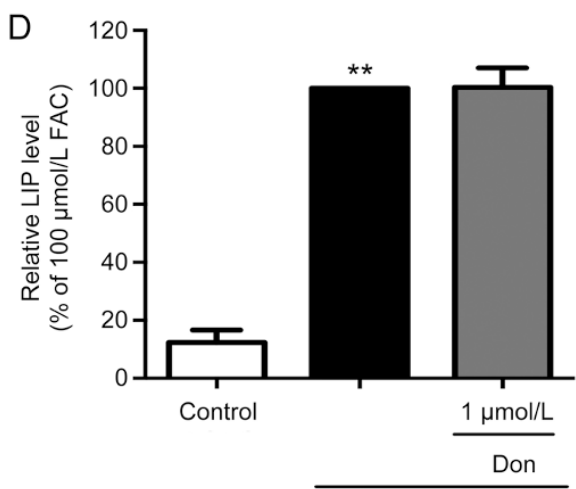

FAC $100 \mu \mathrm{mol} / \mathrm{L}$

Figure 7. Effects of Don on the level of ROS, ATP and LIP in FAC-exposed rat cortical neurons. (A) HupA ( 1 and $10 \mu \mathrm{mol} / \mathrm{L})$ and Don (1 and $10 \mu \mathrm{mol} / \mathrm{L})$ significantly reduced the AChE activity in concentration-dependent manner. $n=3$. (B) Don had no influence on the level of ROS in FAC-exposed neurons. $n=3$. (C) Don had no influence on the level of ATP production in FAC-exposed neurons. $n=4$. (D) Don had no effects on the level of LIP in FAC-exposed neurons. $n=3$. Data were shown as mean \pm SEM. ${ }^{*} P<0.05,{ }^{* *} P<0.01$ vs control group. 
neurodegenerative diseases including $\mathrm{AD}^{[6,40]}$, and there is considerable evidence indicating the cytotoxic effects of iron overload on multiple types of neurons and neuroblastoma cell lines ${ }^{[41-43]}$. Consistently with the results from these previous reports, the addition of exogenous iron to primary cortical neurons induced severe morphological damage and decreases in cell viability (Figure 2). These aberrant changes were significantly and dose-dependently ameliorated by HupA treatment (Figure 2). To our knowledge, this is the first direct evidence regarding the protective effect of HupA against iron overloadinduced injury to neuronal cells, which may shed additional light on the mechanisms underlying the anti-brain damage effects of HupA in animal models involving elevated iron levels in the central nervous system ${ }^{[9,30]}$.

Numerous studies have proven that iron is among the redox-active transition metals that can produce massive amounts of ROS, particularly hydroxyl radicals through the Fenton reaction ${ }^{[37]}$. These overproduced ROS that are triggered by excessive iron have been implicated as critical mediators of eventual neuronal damage ${ }^{[44]}$. Similarly to previous findings ${ }^{[43,45]}$, robust increases in the intracellular ROS levels in primary cortical neurons were observed after $24 \mathrm{~h}$ of exposure to FAC. Interestingly, the detrimental effects of iron were markedly attenuated by HupA treatment (Figure 3), which indicates that the neuroprotective effect of HupA may be at least partially attributable to its anti-oxidative effect. It is highly likely that the anti-oxidative effect of HupA in iron-stimulated neurons is attributable to its enhanced anti-oxidative capacity ${ }^{[20]}$ because HupA has been reported to significantly elevate the ferric reducing antioxidant power (FRAP) ${ }^{[22]}$ and to increase the activities of antioxidant enzymes, including glutathione peroxidase (GSH-Px), superoxide dismutase (SOD), and catalase $(\mathrm{CAT})^{[46]}$. Nevertheless, HupA treatment-induced attenuation of iron-induced oxidative stress is unlikely to be associated with direct iron scavenging because there is no iron-chelating group in the HupA structure (Figure 1). Moreover, we observed a negative iron-chelation activity of HupA on the basis of UV-visible absorption spectra (data not shown).

A growing set of observations indicates that iron plays a detrimental role in mitochondrial dysfunction, which may consequently lead to neuronal damage ${ }^{[14,47,48]}$. The mitochondrion maintains the synthesis of iron-sulfur clusters and heme, which is the most abundant iron-containing prosthetic group in a large variety of proteins. Therefore, a fraction of the incoming iron must proceed through this organelle before reaching its final destination ${ }^{[49]}$. Indeed, numerous studies have proven that excessive iron exposure can induce mitochondrial dysfunction, including ATP decreases ${ }^{[50]}$, disturbances in the electron transport chain ${ }^{[51]}$, and mitochondrial fragmentation ${ }^{[52]}$. Because mitochondria generate most of the energy (ATP) that cells require and play vital roles in many important physiological and pathological events ${ }^{[53-55]}$, we evaluated the ameliorative effects of HupA on mitochondrial dysfunction by measuring ATP levels. The current study revealed that HupA treatment effectively improved mitochondrial function, as demonstrated by the upregulation of the ATP levels in the FAC-treated cortical neurons (Figure 4), and this effect may be closely related to the protective effect of HupA against excessive iron-induced decreases in cell survival. Additionally, ROS and mitochondrial dysfunction have been found to be closely related pathological phenomena in iron-associated neuronal models. ROS cause mitochondrial dysfunction because mitochondria are extremely sensitive to oxidative stress ${ }^{[56]}$. Moreover, mitochondria also produce ROS during the process of ATP generation ${ }^{[57]}$, thus suggesting that the effects of HupA on ROS decreases and mitochondrial protection may act synergistically. Therefore, the obvious ROSdecreasing effect of HupA might also have positively contributed to its beneficial effects on mitochondrial function in the FAC-exposed cortical neurons.

The LIP, which is defined as a low-molecular weight pool of weakly chelated iron, is increased by excessive iron incubation and thus causes cell injury ${ }^{[5,59]}$. In this pool, iron is redox-active and a cellular source that is available for iron metabolism regulation ${ }^{[60,61]}$. Iron regulatory protein-1 (IRP1) functions as an mRNA-binding protein or as an aconitase depending on whether it disassembles or assembles ironsulfur clusters in response to iron deficiency and abundance, respectively ${ }^{[62-65]}$. TfR1 and DMT1 are two major iron uptake proteins with iron-responsive elements (IREs) in their $3^{\prime}$-untranslated regions and are regulated by IRE/IRP ${ }^{[65]}$. Consistently with results from previous studies ${ }^{[6]]}$, the present study demonstrated that iron incubation led to abnormal changes in iron metabolism signaling (Figures 5 and 6). Correspondingly, HupA treatment partly reversed the aberrant elevation of the intracellular LIP level, the down-regulation of TfR1 and DMT1 expression, and the up-regulation of c-aconitase activity after iron exposure. Therefore, in addition to the influences on ROS overproduction and mitochondrial dysfunction, HupA might also exhibit an antagonistic effect on exogenous iron overload-induced abnormal iron metabolism reactions. It has been reported that the enhancement of the LIP promotes ROS formation and mitochondrial dysfunc$\operatorname{tion}^{[47,67]}$, and our finding that HupA decreases the LIP level may contribute to the beneficial effects of HupA against FACinduced aberrant changes in oxidation and mitochondrial function in cortical neurons. HupA may influence the cellular distribution of iron rather than decreasing the iron level via scavenging because the total iron level was not affected by HupA treatment (data not shown).

Because HupA is well known as a potent AChE inhibitor, it is necessary to understand whether the mechanism underlying the beneficial effects of HupA against iron-stimulated neurotoxicity is associated with the classical pharmacological target of HupA. We used the potent AChE inhibitor donepezil for comparison. When AChE activity was equally suppressed ( $\sim 60 \%$ inhibition compared with the control), the Don treatment was unable to regulate the ROS overproduction, mitochondrial dysfunction or intracellular LIP accumulation induced by iron overload (Figure 7). Therefore, the current findings indicate that the beneficial effects of HupA against the iron overload-induced aberrant cascade reaction may not 
be associated with its AChE-inhibiting effects.

In summary, we provided the first demonstration that HupA inhibits iron overload-induced damage in primary neurons and that this effect may be dependent on its regulation of ROS, mitochondrial function and the LIP level and independent of its AChE inhibition (Figure 8). Our study sheds additional light on the neuroprotective mechanism of HupA and may provide important information for the development of potential drugs for the treatment of iron overload-related neurodegenerative disease. However, additional studies are needed to better understand the precise mechanisms by which HupA is involved in this beneficial effect.

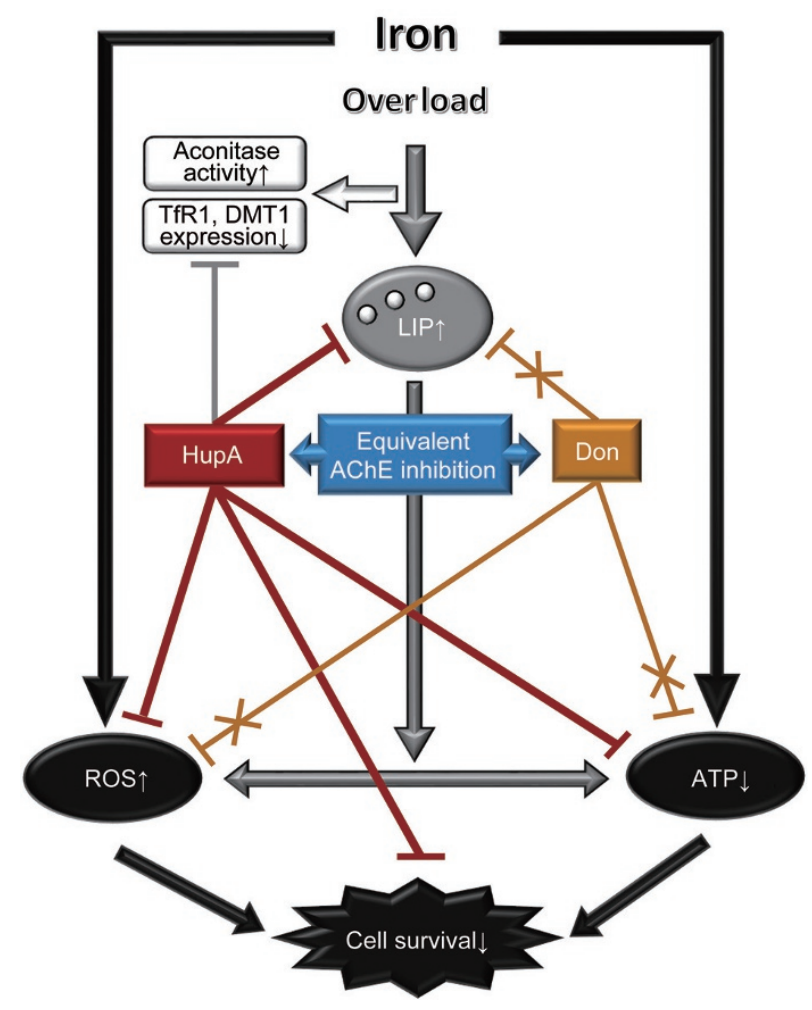

Figure 8. A hypothetical scheme for the mechanism of HupA protection against iron overload induced neurotoxicity. Excessive iron treatment increases the level of LIP, in turn stimulates ROS generation and causes mitochondria dysfunction, which induces more ROS formation and eventually causes neuronal death. HupA significantly reduces the level of LIP and cellular ROS formation and ameliorates the mitochondrial function, and improves the cell viability. Interestingly, the mechanism of HupA protecting against iron overload neurotoxicity may not relevant to its cholinergic effect, in respect that inhibition of AChE activity by another specific AChE inhibitor-Don, to the same extent as that of HupA treatment, has no influence on iron overload induced LIP enhancement, ROS generation and mitochondrial dysfunction. HupA, huperzine A; Don, donepezil.

\section{Acknowledgements}

The authors are grateful to the National Natural Science Foundation of China (№ 81522045 and 31400932).

\section{Author contribution}

Ling-xue TAO, Xi-can TANG, and Hai-yan ZHANG designed the research; Ling-xue TAO, Xiao-tian HUANG, and Yu-ting CHEN performed the research; Ling-xue TAO analyzed data; Ling-xue TAO and Hai-yan ZHANG wrote the paper.

\section{References}

1 Ballard C, Gauthier S, Corbett A, Brayne C, Aarsland D, Jones E. Alzheimer's disease. Lancet 2011; 377: 1019-31.

2 Prince M, Bryce R, Albanese E, Wimo A, Ribeiro W, Ferri CP. The global prevalence of dementia: A systematic review and metaanalysis. Alzheimers Dement 2013; 9: 63-75.e2.

3 Citron M. Alzheimer's disease: strategies for disease modification. Nat Rev Drug Discov 2010; 9: 387-98.

4 Salvador GA, Uranga RM, Giusto NM. Iron and mechanisms of neurotoxicity. Int J Alzheimers Dis 2010; 2011: 1548-90.

5 Ke Y, Qian ZM. Iron misregulation in the brain: a primary cause of neurodegenerative disorders. Lancet Neurol 2003; 2: 246-53.

6 Ward RJ, Zucca FA, Duyn JH, Crichton RR, Zecca L. The role of iron in brain ageing and neurodegenerative disorders. Lancet Neurol 2014; 13: $1045-60$.

7 Bilgic B, Pfefferbaum A, Rohlfing T, Sullivan EV, Adalsteinsson E. MRI estimates of brain iron concentration in normal aging using quantitative susceptibility mapping. Neuroimage 2012; 59: 262535.

8 Hagemeier J, Geurts JJ, Zivadinov R. Brain iron accumulation in aging and neurodegenerative disorders. Expert Rev Neurother 2012; 12: 1467-80.

9 Huang XT, Qian ZM, He X, Gong Q, Wu KC, Jiang LR, et al. Reducing iron in the brain: a novel pharmacologic mechanism of huperzine $A$ in the treatment of Alzheimer's disease. Neurobiol Aging 2014; 35 : 1045-54.

10 Cui ZW, Xie ZX, Wang BF, Zhong ZH, Chen XY, Sun YH, et al. Carvacrol protects neuroblastoma $\mathrm{SH}-\mathrm{SY} 5 \mathrm{Y}$ cells against $\mathrm{Fe}^{2+}$-induced apoptosis by suppressing activation of MAPK/JNK-NF-kappaB signaling pathway. Acta Pharmacol Sin 2015; 36: 1426-36.

11 Bostanci MO, Bagirici F. Neuroprotective effect of aminoguanidine on iron-induced neurotoxicity. Brain Res Bull 2008; 76: 57-62.

12 Bostanci MO, Bas O, Bagirici F. Alpha-tocopherol decreases ironinduced hippocampal and nigral neuron loss. Cell Mol Neurobiol 2010; 30: 389-94.

13 Dixon SJ, Stockwell BR. The role of iron and reactive oxygen species in cell death. Nat Chem Biol 2014; 10: 9-17.

14 Mena NP, Urrutia PJ, Lourido F, Carrasco CM, Nunez MT. Mitochondrial iron homeostasis and its dysfunctions in neurodegenerative disorders. Mitochondrion 2015; 21: 92-105.

15 Weinreb 0, Mandel S, Bar-Am O, Amit T. Iron-chelating backbone coupled with monoamine oxidase inhibitory moiety as novel pluripotential therapeutic agents for Alzheimer's disease: a tribute to Moussa Youdim. J Neural Transm (Vienna) 2011; 118: 479-92.

16 Ritchie CW, Bush AI, Mackinnon A, Macfarlane S, Mastwyk M, MacGregor L, et al. Metal-protein attenuation with iodochlorhydroxyquin (clioquinol) targeting Abeta amyloid deposition and toxicity in Alzheimer disease: a pilot phase 2 clinical trial. Arch Neurol 2003; 60: 1685-91.

17 Bush Al. Metal complexing agents as therapies for Alzheimer's disease. Neurobiol Aging 2002; 23: 1031-8.

18 Crapper McLachlan DR, Dalton AJ, Kruck TP, Bell MY, Smith WL, Kalow W, et al. Intramuscular desferrioxamine in patients with Alzheimer's disease. Lancet 1991; 337: 1304-8. 
19 Zhang HY, Zheng CY, Yan H, Wang ZF, Tang LL, Gao X, et al. Potential therapeutic targets of huperzine A for Alzheimer's disease and vascular dementia. Chem Biol Interact 2008; 175: 396-402.

20 Little JT, Walsh S, Aisen PS. An update on huperzine A as a treatment for Alzheimer's disease. Expert Opin Inv Drug 2008; 17: 209-15.

21 Wang R, Yan H, Tang XC. Progress in studies of huperzine A, a natural cholinesterase inhibitor from Chinese herbal medicine. Acta Pharmacol Sin 2006; 27: 1-26.

22 Pohanka M, Hrabinova M, Zemek F, Drtinova L, Bandouchova H, Pikula J. Huperzine induces alteration in oxidative balance and antioxidants in a guinea pig model. Neuro Endocrinol Lett 2011; 32 : 95-100.

23 Xiao XQ, Wang R, Tang XC. Huperzine A and tacrine attenuate betaamyloid peptide-induced oxidative injury. J Neurosci Res 2000; 61: 564-9.

24 Xiao XQ, Zhang HY, Tang XC. Huperzine A attenuates amyloid betapeptide fragment 25-35-induced apoptosis in rat cortical neurons via inhibiting reactive oxygen species formation and caspase-3 activation. J Neurosci Res 2002; 67: 30-6.

25 Xiao XQ, Yang JW, Tang XC. Huperzine A protects rat pheochromocytoma cells against hydrogen peroxide-induced injury. Neurosci Lett 1999; 275: 73-6.

26 Mao XY, Zhou HH, Li X, Liu ZQ. Huperzine A alleviates oxidative glutamate toxicity in hippocampal HT22 cells via activating BDNF/ TrkB-dependent PI3K/Akt/mTOR signaling pathway. Cell Mol Neurobiol 2016; 36: 915-25.

27 Wang LM, Han YF, Tang XC. Huperzine A improves cognitive deficits caused by chronic cerebral hypoperfusion in rats. Eur J Pharmacol 2000; 398: 65-72.

28 Shang YZ, Ye JW, Tang XC. Improving effects of huperzine A on abnormal lipid peroxidation and superoxide dismutase in aged rats. Acta Pharmacol Sin 1999; 20: 824-8.

29 Yang L, Ye CY, Huang XT, Tang XC, Zhang HY. Decreased accumulation of subcellular amyloid-beta with improved mitochondrial function mediates the neuroprotective effect of huperzine A. J Alzheimers Dis 2012; 31: 131-42.

30 Lu H, Jiang M, Lu L, Zheng G, Dong Q. Ultrastructural mitochondria changes in perihematomal brain and neuroprotective effects of Huperzine A after acute intracerebral hemorrhage. Neuropsychiatr Dis Treat 2015; 11: 2649-57.

31 Wu J, Hua Y, Keep RF, Nakamura T, Hoff JT, Xi G. Iron and ironhandling proteins in the brain after intracerebral hemorrhage. Stroke 2003; 34: 2964-9.

32 Casadesus G, Smith MA, Zhu X, Aliev G, Cash AD, Honda K, et al. Alzheimer disease: evidence for a central pathogenic role of ironmediated reactive oxygen species. J Alzheimers Dis 2004; 6: 165-9.

33 Ho KP, Li L, Zhao L, Qian ZM. Genistein protects primary cortical neurons from iron-induced lipid peroxidation. Mol Cell Biochem 2003; 247: 219-22.

34 Epsztejn S, Kakhlon O, Glickstein H, Breuer W, Cabantchik I. Fluorescence analysis of the labile iron pool of mammalian cells. Anal Biochem 1997; 248: 31-40.

35 Gonzalez D, Drapier JC, Bouton C. Endogenous nitration of iron regulatory protein-1 (IRP-1) in nitric oxide-producing murine macrophages: further insight into the mechanism of nitration in vivo and its impact on IRP-1 functions. J Biol Chem 2004; 279: 43345-51.

36 Ellman GL, Courtney KD, Andres V Jr, Feather-Stone RM. A new and rapid colorimetric determination of acetylcholinesterase activity. Biochem Pharmacol 1961; 7; 88-9.

37 Castellani RJ, Moreira PI, Liu G, Dobson J, Perry G, Smith MA, et al. Iron: the Redox-active center of oxidative stress in Alzheimer disease.
Neurochem Res 2007; 32: 1640-5.

38 Lei Y, Yang L, Ye CY, Qin MY, Yang HY, Jiang HL, et al. Involvement of intracellular and mitochondrial abeta in the ameliorative effects of Huperzine A against oligomeric abeta42-induced injury in primary rat Neurons. PLoS One 2015; 10: e0128366.

39 Wang R, Xiao XQ, Tang XC. Huperzine A attenuates hydrogen peroxideinduced apoptosis by regulating expression of apoptosis-related genes in rat PC12 cells. Neuroreport 2001; 12: 2629-34.

40 Silvestri L, Camaschella C. A potential pathogenetic role of iron in Alzheimer's disease. J Cell Mol Med 2008; 12: 1548-50.

41 Bishop GM, Robinson SR. Quantitative analysis of cell death and ferritin expression in response to cortical iron: implications for hypoxia-ischemia and stroke. Brain Res 2001; 907: 175-87.

42 Hayter CL, Bishop GM, Robinson SR. Pharmacological but not physiological concentrations of melatonin reduce iron-induced neuronal death in rat cerebral cortex. Neurosci Lett 2004; 362: 1824.

43 Salvador GA, Oteiza PI. Iron overload triggers redox-sensitive signals in human IMR-32 neuroblastoma cells. Neurotoxicology 2011; 32: 75-82.

44 Dixon SJ, Stockwell BR. The role of iron and reactive oxygen species in cell death. Nat Chem Biol 2014; 10: 9-17.

45 He Q, Song N, Xu HM, Wang R, Xie JX, Jiang H. Alpha-synuclein aggregation is involved in the toxicity induced by ferric iron to SK-N-SH neuroblastoma cells. J Neural Transm (Vienna) 2011; 118: 397-406.

46 Xiao XQ, Wang R, Tang XC. Huperzine A and tacrine attenuate betaamyloid peptide-induced oxidative injury. J Neurosci Res 2000; 61: 564-9.

47 Pelizzoni I, Macco R, Morini MF, Zacchetti D, Grohovaz F, Codazzi F. Iron handling in hippocampal neurons: activity-dependent iron entry and mitochondria-mediated neurotoxicity. Aging Cell 2011; 10: 17283.

48 Sripetchwandee J, Sanit J, Chattipakorn N, Chattipakorn SC. Mitochondrial calcium uniporter blocker effectively prevents brain mitochondrial dysfunction caused by iron overload. Life Sci 2013; 92 : 298-304.

49 Urrutia PJ, Mena NP, Nunez MT. The interplay between iron accumulation, mitochondrial dysfunction, and inflammation during the execution step of neurodegenerative disorders. Front Pharmacol 2014; 5: 38.

50 Pardo Andreu GL, Inada NM, Vercesi AE, Curti C. Uncoupling and oxidative stress in liver mitochondria isolated from rats with acute iron overload. Arch Toxicol 2009; 83: 47-53.

51 Gao X, Campian JL, Qian M, Sun XF, Eaton JW. Mitochondrial DNA damage in iron overload. J Biol Chem 2009; 284: 4767-75.

52 Park J, Lee DG, Kim B, Park SJ, Kim JH, Lee SR, et al. Iron overload triggers mitochondrial fragmentation via calcineurin-sensitive signals in HT-22 hippocampal neuron cells. Toxicology 2015; 337: 39-46.

53 Carafoli E, Lehninger AL. Binding of adenine nucleotides by mitochondria during active uptake of $\mathrm{CA}^{++}$. Biochem Biophys Res Commun 1964; 16: 66-70.

54 Hirsch T, Marchetti P, Susin SA, Dallaporta B, Zamzami N, Marzo I, et al. The apoptosis-necrosis paradox. Apoptogenic proteases activated after mitochondrial permeability transition determine the mode of cell death. Oncogene 1997; 15: 1573-81.

55 Beal MF. Mitochondria take center stage in aging and neurodegeneration. Ann Neurol 2005; 58; 495-505.

56 Gruber J, Fong S, Chen CB, Yoong S, Pastorin G, Schaffer S, et al. Mitochondria-targeted antioxidants and metabolic modulators as pharmacological interventions to slow ageing. Biotechnol Adv 2013; 31: 563-92. 
57 Shadel GS, Horvath TL. Mitochondrial ROS signaling in organismal homeostasis. Cell 2015; 163: 560-9.

58 Staubli A, Boelsterli UA. The labile iron pool in hepatocytes: prooxidant-induced increase in free iron precedes oxidative cell injury. Am J Physiol 1998; 274: G1031-7.

59 Li Y, Deng Y, Tang Y, Yu H, Gao C, Liu L, et al. Quercetin protects rat hepatocytes from oxidative damage induced by ethanol and iron by maintaining intercellular liable iron pool. Hum Exp Toxicol 2014; 33: 534-41.

60 Kakhlon 0, Cabantchik ZI. The labile iron pool: characterization, measurement, and participation in cellular processes. Free Radic Biol Med 2002; 33: 1037-46.

61 Kruszewski M. Labile iron pool: the main determinant of cellular response to oxidative stress. Mutat Res 2003; 531: 81-92.

62 Ke Y, Qian ZM. Brain iron metabolism: neurobiology and neuro- chemistry. Prog Neurobiol 2007; 83: 149-73.

63 Roy CN, Blemings KP, Deck KM, Davies PS, Anderson EL, Eisenstein RS, et al. Increased IRP1 and IRP2 RNA binding activity accompanies a reduction of the labile iron pool in HFE-expressing cells. J Cell Physiol 2002; 190: 218-26.

64 Ho KP, Xiao DS, Ke Y, Qian ZM. Exercise decreases cytosolic aconitase activity in the liver, spleen, and bone marrow in rats. Biochem Biophys Res Commun 2001; 282: 264-7.

65 Eisenstein RS. Iron regulatory proteins and the molecular control of mammalian iron metabolism. Annu Rev Nutr 2000; 20: 627-62.

66 Rouault TA. The role of iron regulatory proteins in mammalian iron homeostasis and disease. Nat Chem Biol 2006; 2: 406-14.

67 Brissot P, Ropert M, Le Lan C, Loreal O. Non-transferrin bound iron: a key role in iron overload and iron toxicity. Biochim Biophys Acta 2012; 1820: 403-10. 